\title{
Equality \& Diversity Perspectives for the Proficiency in English Assessment for IMGs
}

\begin{abstract}
The story of a West Midlands General Practitioner who faced the fearsome prospect of deportation and severance from her young family due to expiry of her English proficiency test after 2 years- highlights the lack of consultation, awareness, empathy and dignity that is perceived by international medical graduates in the UK. What is most alarming is that evidence of working as a GP in the UK for 8 years, communicating with patients and colleagues in English - and passing all the standardised professional examinations set by the medical royal colleges was not considered sufficient for her to be assessed to have the minimum requirements for her permit/ leave to remain to be renewed. The mental anguish and stress that a frontline GP has to face is totally avoidable.
\end{abstract}

The NHS, GMC and Department of Health and Social Care needs to have robust consultation with the Home Office department on making the rules sensitive and meaningful and applied with awareness, understanding and compassion that is critical for the wellbeing of the healthcare workforce- and the benefit of our patients.

Keywords

International English Language Test, International medical graduate, General Practitioner, Department of Health and Social Care

\section{Background}

Assessment of proficiency in English has been established as a prerequisite for admission to higher education institutions and for migration or employment in many predominantly English speaking countries for over five decades. Tests of English as Foreign Language (TOEFL) and International English Language Test (IELTS) ${ }^{1}$ are taken by almost 3-4 million applicants each year and accepted in the USA, Canada, UK, Australia and New Zealand. There are variations in the content depending on the stated purpose of the test- employment, higher studies or migration. Both the tests are demonstrated to produce consistent and reproducible results with good skills: reliability in assessment of the four language listening,

\section{EDITORIAL}

Indranil Chakravorty PhD FRCP

Faculty of Life \& Medical

Sciences, University of

Hertfordshire, Hatfield, UK

indranil.chakravorty@nhs.uk

Cite as:

Chakravorty, I. (2021) Equality and diversity perspectives for the proficiency in English assessments for IMGs. The Physician vol 7: Issue 2: Art 2 ePub 25.10.21 DOI Https://doi.org/10.38192/1.7.2.2

Article Information

Submission 25.10.21

Published 25.10.21

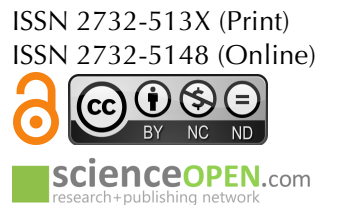


reading, writing and speaking. They also feature a one-on-one, face-to-face speaking test and claim to ensure that the questions are extensively trialled with people from different cultures to confirm they are appropriate and fair. There is little context validity data publicly available.

Perceptions of test-takers are variable. Even as there was some evidence of support for the test as a fair measure of students' English capacity, the extent to which it actually reflected their language capabilities was open to question. While there was a sense of procedural fairness evident in the way the test was constructed, and how it was enacted, test repetition showed substantial variations across test sittings for the same individuals; in their experiences of engaging in English in the host society (context) and did not guarantee comparative validity of proficiency between individuals with similar scores. In addition, there were perceptions of whether IELTS was a vehicle for raising revenue and for justifying restrictive immigration policies, thus raising questions about the justness of the test. ?

These high-stakes, high-pressure tests have become firmly entrenched as a global gatekeeping institution, regulating the international flows of people for migration and academic study. Acknowledging the importance of equality and fairness, such a high-stakes test should also achieve differential validity through measures to avoid test bias in terms of factors such as gender, ethnic origin, first language, colonial, political, cultural, religious and regional impact. ${ }^{3}$ Fairness, refers to the technical quality of the test while justice encompasses the values implicit in test constructs, and the social uses to which language tests may be put. It illustrates the potential usefulness of the distinction by discussing the growing international practice of the use of language tests within citizenship procedures. ${ }^{4}$

Yet the perspectives of one of the key stakeholders - the test-takers themselves appear to be ignored. A critique of certain features of
IELTS suggested implementable solutions to enable IELTS to become a more democratic and humane testing system, imbued with potential for learning, for the benefit of its test-takers. As with other tests, public and institutional trust in IELTS represents an unwritten social contract between the tester (the dominator) and the test-taker (the dominated). Pearson ${ }^{5}$ suggested that changes are required to the administration and design of IELTS based on democratization, humanization, and the institutionalization of formative feedback. Democratization both protects and empowers test-takers by enabling their meaningful participation and involvement in the assessment process and recognises the consequential impacts on their lives and livelihoods. While humanising language testing involves reducing its perceived severity, being aware of affective responses and trying to minimize them, attributing genuine concern for people's well-being during the test, and making the test meaningful and useful for candidates.

Organisations including HEls' should be encouraged to interpret IELTS scores in the wider context of the whole applicant. Pearson also recommends that co-owners of IELTS should implement appropriate systems for the provision of meaningful and constructive feedback on test performance beyond current practices.

\section{The Context of Healthcare Professionals}

The argument that healthcare education, training and service provision requires not only a high level of academic ability particularly in certain science based subjects but a higher degree of linguistic command in order to understand, interpret language clues as well as manage effective communication with patients or relatives is a robust one. Where all the evidence does indeed become weak is in the context of empathy, cultural awareness and emotional intelligence which are equally important, if not more important than a demonstrated command of the language. It has been argued that doctors who have lower scores in their clinical knowledge component (of Professional Linguistic Assessment Board examinations) were 
academically inferior to their UK peers (based on outcomes of Annual Review of Career Progression- ARCP); and those with lower IELTS scores are more likely to be referred to or censured by the regulator in fitness to practice cases. ${ }^{6}$ Based on this review in 2016, the UK General Medical Council decided to tighten the PLAB clinical test scenarios, pass thresholds, limit the number of attempts allowed and increase the threshold for IELTS scores required for registration.

However, there are fundamental flaws in both these arguments, which have since come to light and thus makes these changes unsafe and ethically indefensible. A review of ARCP process and outcomes by HEE demonstrated considerable variability in the way panels interpreted the evidence, weaknesses in how evidence and feedback was presented by educational supervisors and differential outcomes based on protected characteristics. ${ }^{7}$ In addition, GMC's fitness to practice referrals are likely to represent significant structural bias against doctors from minority enthnic backgrounds as well as international medical graduates. ${ }^{8,9}$

The equality and diversity assessment of PLAB is still to be demonstrated and it is likely to be representative of the structural differences that exist across the spectrum of medical and healthcare professions. ${ }^{10}$ While it is widely accepted that English has become globalized, there are numerically more English speakers and those that receive their entire education in English then in countries such as the UK and New Zealand. In the healthcare sector there are over $41 \%$ of the medical professionals who have either been born or trained overseas. Hence, it is time that the design itself moves away from the Anglophone voices in the Listening test, and incorporates non-native speaker ones. Such a move confers greater validity on variants to inner-circle English, emphasizing the reality of the truly international nature of English today. ${ }^{5}$
English Requirement and the Home Office Case Study

The recent story of Dr Soumitri Chakraborty, a General Practitioner in the West Midlands illustrates another seemingly unfair and dehumanising policy of the UK Home Office. Dr Chakraborty presented her story at the recent silver jubilee conference of the British Association of Physicians of Indian Origin in Birmingham. She trained in India and has been working as a GP in the UK for the last 8 years. Her husband and 10 year old daughter are both UK citizens. However, in spite of providing evidence of her success in the examinations of the Royal College of GPs, being on the GMC register and submitting her evidence as competency in English, she was forced to undertake a further IELTS test to demonstrate her competency in English. While waiting for the results, she described going through the incredible stress of facing deportation and severance from her family. ${ }^{11}$ Not only has $\mathrm{Dr}$ Chakraborty undertaken her entire education in English and her medical degree, her command of 2 other languages (Bengali and Hindi) are an asset in serving her diverse population in the West Midlands, which appear not to make an iota of difference to the UK Home Office.

The second issue with her case was the arbitrary time-limit set on the validity of the previous IELTS score which is set at 2 years. It is conceptually acceptable that a non-native English speaker, who undertakes a course on English in preparation for arrival in the UK, then gets delayed and therefore loses her acquired skill over 2 years- and has to take another test to demonstrate her competency. What is not acceptable is someone who then lives and works in an English speaking country, demonstrates her skill not-only through her work but through standardised assessments (RCGP examinations) then has to take the IELTS again.

This type of draconian and dehumanising experience (as described by Dr Chakraborty0 is based on a set of archaic rules applied without understanding, awareness or compassion - thus making a mockery of the stated principles of 
empathy, kindness that the NHS People's Plan 12,13 envisions.

\section{What do we need to do?}

The IELTS assessment requirement for obtaining a work permit or an indefinite leave to remain is another area of controversy, which is beyond the scope of this editorial. However, the requirement for a high threshold score in IELTS for academic roles or for medical professionals is relevant to safe practice, effective communication. In order for IELTS to meet the requirements of context validity, any research in this area should relate to performance as a doctor, feedback from workplaces including patients or colleagues and, although somewhat flawed, communication elements of the professional assessments conducted by the medical royal colleges. The UK Home Office offers certain exceptional circumstances when the Language requirements are waived. Demonstration of having an active employment in a role which requires a good command of English should and must be one of them. It is imperative that the GMC, NHS Employers and Department of Health and Social Care has some robust consultation with doctors representatives and brings such a loophole to a speedy closure. The UK healthcare workforce is facing an unprecedented winter of incredible workload with a burnt out staff- this is not a time for complacency on wellbeing and support.

\section{References}

1. IELTS Home of the IELTS English Language Test. Accessed October 25, 2021. https://www.ielts.org/

2. Hamid MO, Hardy I, Reyes V. Test-takers' perspectives on a global test of English: questions of fairness, justice and validity. Lang Test Asia. 2019;9(1):16. doi:10.1186/s40468-019-0092-9

3. Association of Language Testers in Europe, ed. Multilingualism and Assessment: Achieving Transparency, Assuring Quality, Sustaining Diversity: Proceedings of the ALTE Berlin Conference, May 2005. Cambridge University Press; 2008.

4. McNamara T, Ryan K. Fairness Versus Justice in Language Testing: The Place of
English Literacy in the Australian Citizenship Test. Language Assessment Quarterly. 2011;8(2):161-178. doi:10.1080/15434303.2011.565438

5. Pearson WS. Critical perspectives on the IELTS test. ELT Journal. 2019;73(2):197206. doi:10.1093/elt/ccz006

6. Tiffin DPA, Illing J, Webster DL, McLachlan JC. The Validity of the Professional and Linguistic Assessments Board (PLAB) Exam: Research Report. :41.

7. Annual review of competency progression. Health Education England. Published November 21, 2017. Accessed October 25, 2021. https://www.hee.nhs.uk/ourwork/annual-review-competencyprogression

8. Kline R. The snowy white peaks of the NHS: a survey of discrimination in governance and leadership and the potential impact on patient care in London and England. doi:10.22023/mdx.12640421.v1

9. Fair to refer? Accessed June 19, 2021. https://www.gmc-uk.org/about/what-wedo-and-why/data-and-research/researchand-insight-archive/fair-to-refer

10. 2021: Bridging the Gap 2021- Report | Sushruta Journal of Health Policy \& Opinion. Accessed October 25, 2021. https://www.sushrutajnl.net/index.php/sus hruta/issue/view/13

11. Soumitri Chakraborty. \#GPCrisis \#Visa I am working in NHS for last 8 years, working as a \#gp after doing my postgraduate training from @ rcgp and even after all these @ukhomeoffice thinks I'm not good in English and asking for more documents@sima_kotecha @Keir_Starmer @bbcmtd@sajidjavid@pritipatel. $@$ @rishnakolibabe. Published October 15, 2021. Accessed October 25, 2021. https://twitter.com/krishnakolibabe/status/1 448938998924185617

12. NHS England» Our NHS People Promise. Accessed February 3, 2021. https://www.england.nhs.uk/ournhspeople /online-version/lfaop/our-nhs-peoplepromise/

13. NHS England» We are the NHS: People Plan for 2020/2021 - action for us all. Accessed September 28, 2020. https://www.england.nhs.uk/ournhspeople / 